\title{
COLORANTES DE CURCUMA LONGA, ESTUDIO DE SU PROBABLE EFECTO ANTIINFLAMATORIO ANALGÉSICO-ANTIRADICAL LIBRE
}

\author{
CESAR M. FUERTES RUITON, AMERICO CASTRO LUNA, \\ ROSARIO CARREÑO $Q$ Y CARMEN ARANA AVILA
}

Instituto de Química Orgánica Aplicada a la Farmacia. U.N.M.S.M.

\section{INTRODUCCIÓN}

Los rizomas de Curcuma longa recolectados en la localidad de Pucallpa por extracción etanólica en frío, producen por lo menos tres curcuminoides coloreados estimados mediante cromatografía en capa fina y cromatografía líquida de alta performance HPLC (Fig. 1). Cada colorante ha sido aislado mediante cromatografía en columna y las estructuras analizadas por espectroscopía IR (Fig. 2). El modelo de estructura de la curcumina y los curcuminoides similar a los carotenoides hace suponer que las insaturaciones pueden absorber oxígeno y radicales libres, además de implicar un mecanismo antiinflamatorio (Fig. 3).

En conexión con los trabajos de MISRA y Col (1972) acerca de la comparación de la actividad antiradicálica de la enzima superóxido dismutasa correlacionada con la oxidación o autooxidación de la epinefrina; y el trabajo de SREEJAYAN y Col (1997) que utiliza el óxido nítrico para comprobar la acción antioxidante de estructuras químicas, es posible establecer el comportamiento de los curcuminoides.

\section{MATERIAL Y MÉTODOS}

Los colorantes fueron desecados en un equipo de liofilización de los Laboratorios LBM Colichón. Los cromatogramas HPLC se determinaron en un equipo Perkin Elmer con columnas LiChrosorb RP $18250 \times 4 \mathrm{~mm}$ i. d. y Zobaz Ods $250 \times 4,6$ mm i. d.

Los espectros IR fueron registrados en espectrofotómetro Perkin Elmer 257. Las lecturas de la oxidación de epinefrina y de su inhibición fueron determinados en un espectrofotómetro Milton Roy Spectronic 20D.

\section{- Determinación del efecto antiinflamatorio}

Modelo: Edema plantar en ratas inducido por carragenina descrito por Winter et al modificado por Sughisila et al (1981).

- Se pesaron los animales, se marcaron y se distribuyeron en 6 grupos de 4 ratas cada uno.

- Para iniciar se determinaron los volúmenes basales de las patas normales utilizando el pletismómetro manual.

- Se administraron las drogas y los estándares en las dosis establecidas vía personal utilizando la sonda. 
- Luego de $60 \mathrm{~min}$. se provocó la inflamación mediante la administración de $0.01 \mathrm{ml}$ de carragenina al $3 \%$.

- Cada hora y durante 4 horas se controló la evolución de la pata inflamada del grupo contratado y estándar.

\section{- Determinación de la actividad antiradical libre (antioxidante)}

Se ensayó con el pigmento amarillo naranja y con el extracto total en metanol de Curcuma longa.

Condiciones de trabajo: la oxidación de la epinefrina se produjo a $\mathrm{pH}$ 10,2 en una mezcla de reacción que contiene $3 \times 10^{-1} \mathrm{M}$ de epinefrina, $1 \times 10^{-4} \mathrm{M}$ de EDTA y buffer de carbonato de sodio a pH 10,2 y $0,05 \mathrm{M}$ incubado a $30^{\circ} \mathrm{C}$ por I minuto. La muestra problema disuelta en metanol fue sometida a las mismas condiciones de trabajo y sobre la mezcla anterior. Tanto el comportamiento de la curcumina como del extracto fueron seguidos leyendo las absorbancias a $480 \mathrm{~nm}$ durante 5 minutos.

\section{RESULTADOS}

Los resultados en la determinación de la acción antiinflamatoria se observa en las Figs. 4 y 5 , donde se puede apreciar la acción de la curcumina, del extracto total y de un curcuminoide, comparado con el efecto del piroxicam y la dexametasona. Los resultados están expresados en la disminución de la inflamación.

La disminución de la inflamación se produce a una dosis de $125 \mathrm{mg} / \mathrm{kg}$ de peso con la curcumina, dando lugar a una disminución de la inflamación equivalente al $27,5 \%$, con respecto al grupo blanco (Figs. 6 y 7 ).

En la determinación de la acción antiradical libre (antioxidante) se produjo buenos resultados con el extracto total disuelto en metanol y mejor con la curcumina. El color rojo que se produce por autooxidación de la epinefrina es inhibido por el extracto y por la curcumina (Fig. 8).

\section{DISCUSIÓN}

Los curcuminoides de los rizomas de Curcuma longa, presentan acción antiinflamatoria, especialmente la curcumina. La administración subcutánea de carragenina a nivel de la aponeurosis plantar de la rata provoca una reacción de carácter inflamatoria, mediada por la liberación de autacoides, se evidencia entonces la formación de un edema. Este se mide mediante un pletismómetro. la diferencia de volúmenes $(\Delta \mathrm{V})$ de la pata inflamada con respecto al basal normal controlada cada hora representará el curso de la inflamación. $\mathrm{El} \Delta \mathrm{V}$ de la pata del animal tratado con la droga en estudio se compara porcentualmente con el $\Delta \mathrm{V}$ del animal control a la misma hora. Para el control se usó piroxicam y dexametasona.

En cuanto a la acción antiradical libre, por el hecho de que el ensayo es semejante a la acción de la enzima superóxido dismutasa contra el radical libre superóxido y estudiado en paralelo con SODM y epinefrina, se ha comprobado fehacientemente que la curcumina o el extracto inhibe fuertemente la auto oxidación de la epinefrina a $\mathrm{pH} 10,2$. 
La epinefrina a $\mathrm{pH} 10,2$ se oxida hacia adenocromo de color rojo cuya máxima absorción es de $480 \mathrm{~mm}$. La oxidación que es rápida se protege en presencia de curcumina y del extracto metanólico de Cúrcuma longa (Fig. 8).

\section{CONCLUSIONES}

1. El curcuminoide curcumina a la dosis de $125 \mathrm{mg} / \mathrm{kg}$ de peso tiene una actividad antiinflamatoria de disminución de la inflamación del $27.5 \%$ a la cuarta hora con respecto al grupo blanco.

2. En extracto posee hasta $55 \%$ de disminución de la inflamación.

3. No tiene acción analgésica.

4. La curcumina y el extracto metanólico de Cúrcuma longa inhibe fuertemente la autooxidación de la epinefrina, por lo tanto tiene una acción antiradical libre igual a la enzima superóxido dismutasa (SOD).

\section{REFERENCLAS BIBLIOBRÁFICAS}

1. Manual de Técnicas de Investigación CYTED Programa lbereamericano de Ciencias y Tecnología para el Desarrollo 1995.

2. GOODMAN GILMAN A. Las Bases Farmacológicas de la Terapéutica. Vol. 1 Novena Edición Editorial McGRAW-HILL INTERAMERICANA México, 1996.

3. MISRA HARA P. and FRIDOVICH I. J. Biological Chem. 1972: 247 (10), 3170-3175.

4. SREEJA Y. and RAO M. N. A. J. Pjarm. Pharmacol. 1997: 49, 105-107.

\section{ANÁLISIS POR HPLC DE CURCUMINOIDES} DE CURCUMA LONGA

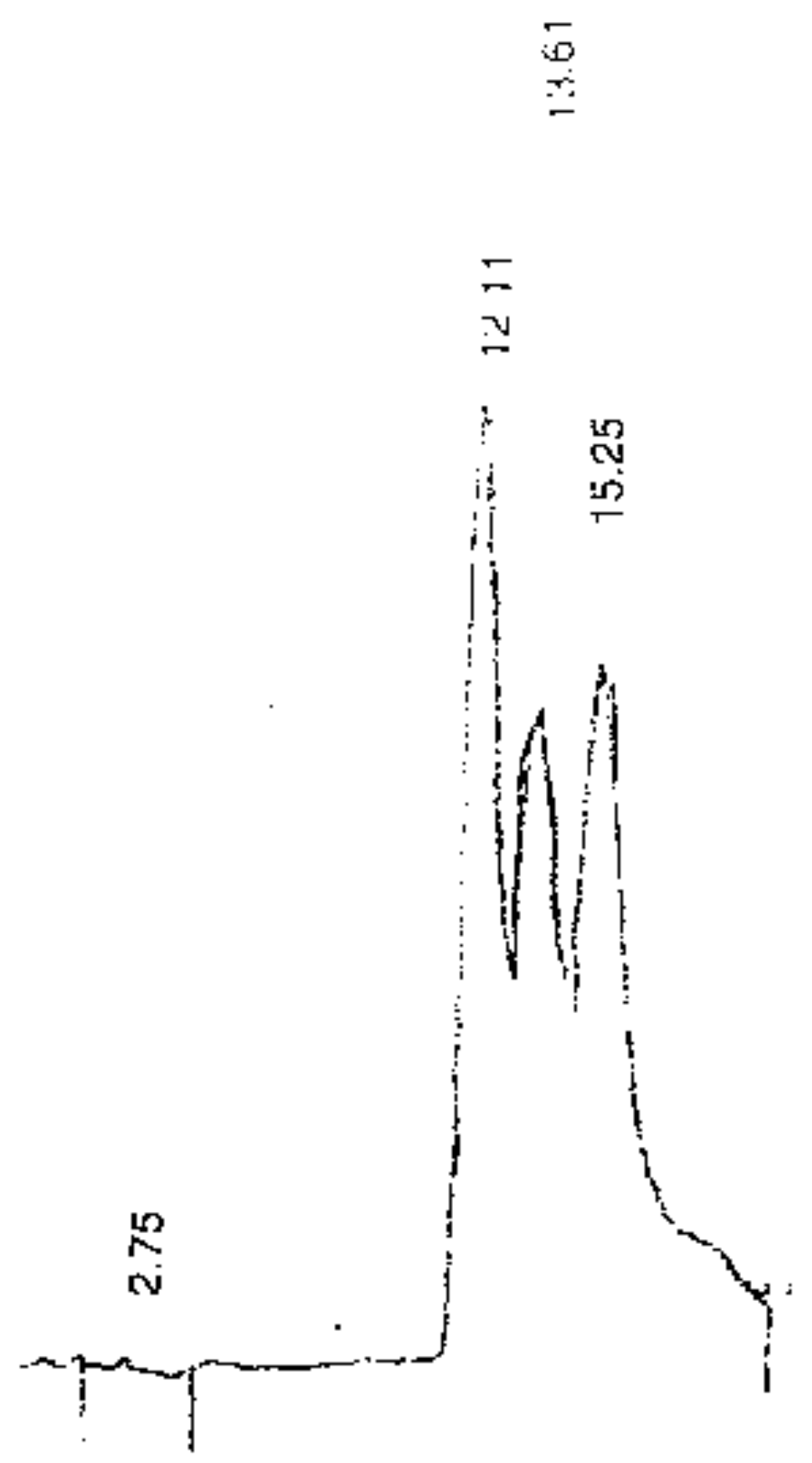

Tiempo de retencion (RT) de Curcumina 12,11

FIG. $N^{\circ} 1$ 


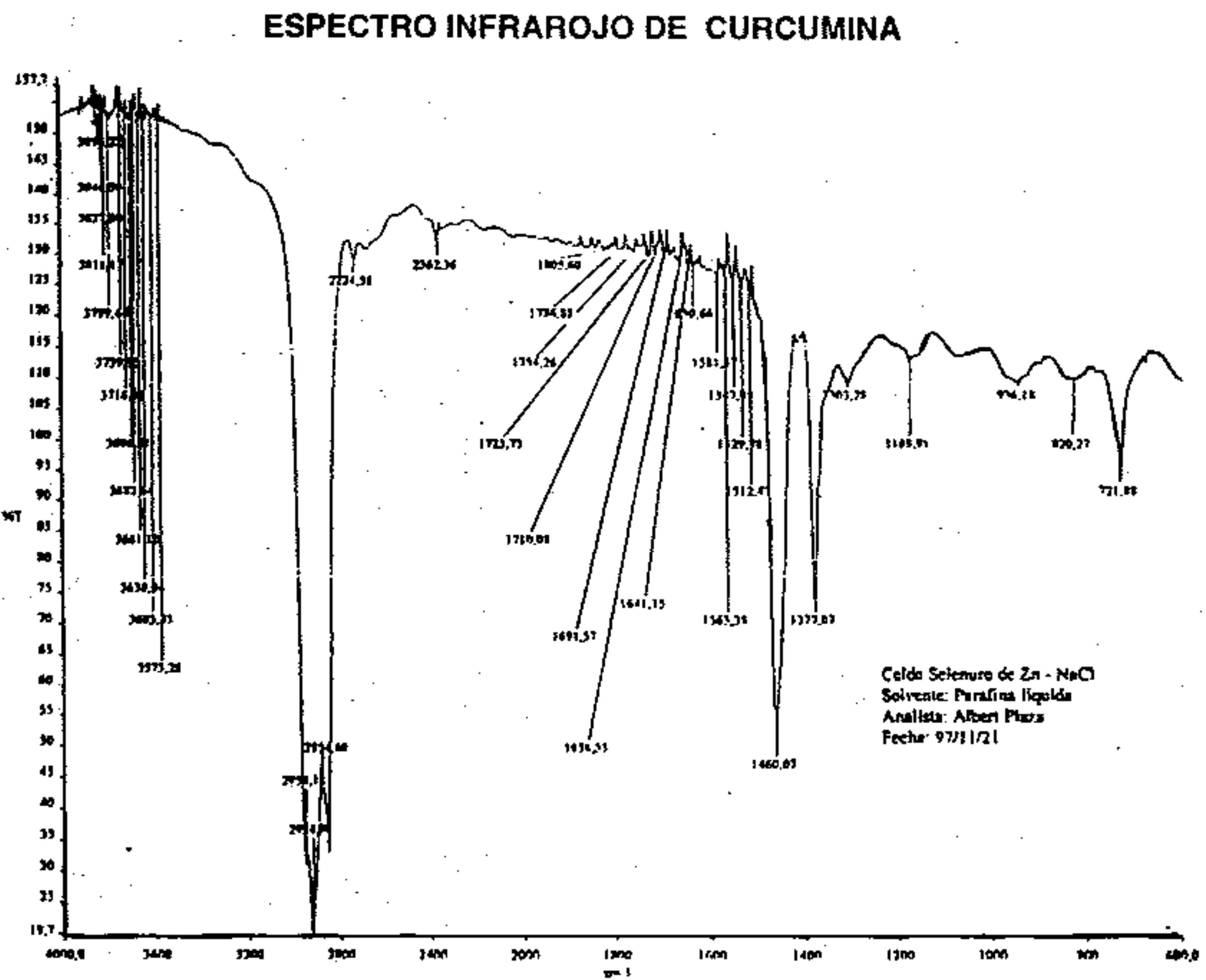

FIG. $\mathrm{N}^{\circ} 2$

\section{ESTRUCTURA DE LA CURCUMINA Y}

COMPONENTES RELACIONADOS

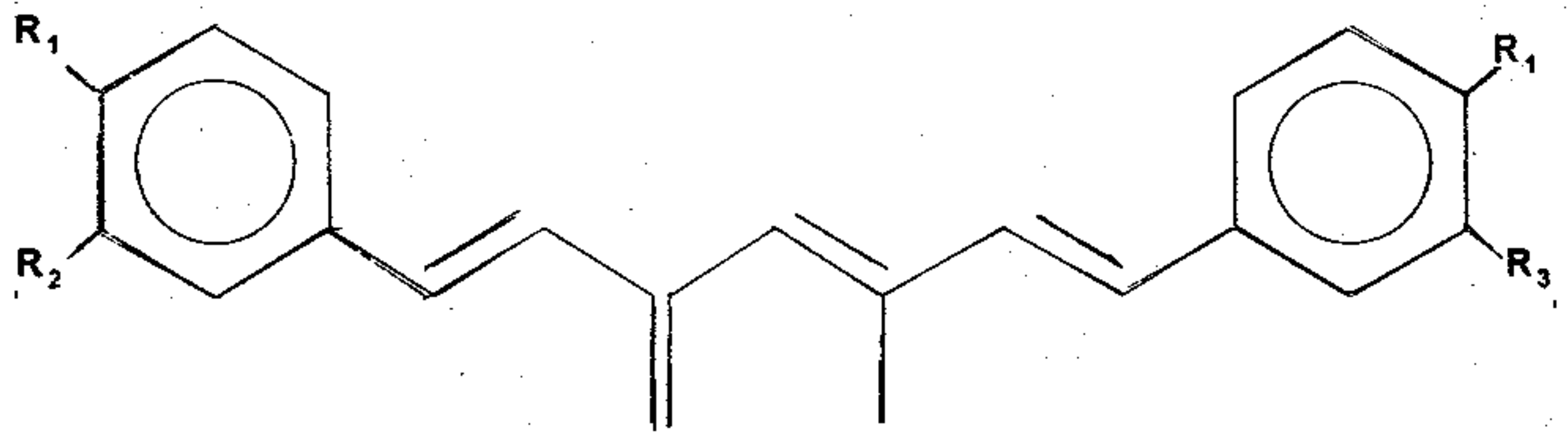

$\mathrm{O} \quad \mathrm{OH}$

$\begin{array}{lll}R_{1} & R_{2} & R_{3}\end{array}$

Curcumina $\mathrm{OH}$ OMe $\mathrm{OMe}$

Dimetoxicurcumina $\mathrm{OH}$ OMe $\mathrm{H}$

Bis dimetoxicurcumina $\mathrm{OH} \mathrm{H} \quad \mathrm{H}$ 


\section{RESULTADOS DE LA ACCIÓN ANTIINFLMATORIA DE LA CURCUMINA Y DEL EXTRACTO METANOLICO DE Curcuma longa}

\begin{tabular}{|c|c|c|c|c|c|c|}
\hline \multirow{2}{*}{ GRUPO } & \multirow{2}{*}{ Doș!S } & \multicolumn{5}{|c|}{$\Delta V=$ Volumen del control - volumen del animal tratado } \\
\hline & & 0 Hrs & 1ra. Hora & 2da. Hora & 3ra. Hora & 45a. Hora \\
\hline Blanco & Blanco & 0 & 0,95 & 1,65 & 1,85 & 2,00 \\
\hline Muestra 1 & $6,25 \mathrm{mg} / \mathrm{Kg}$ & 0 & 0,75 & 1,00 & 1,45 & 2,25 \\
\hline (polvo rojizo) & $12,5 \mathrm{mg} / \mathrm{Kg}$ & 0 & 0,80 & 1,20 & 1,90 & 2,35 \\
\hline & $125 \mathrm{mg} / \mathrm{kg}$ & 0 & 0,80 & 1.20 & 1,90 & 1,45 \\
\hline Muestra 2 & $12,5 \mathrm{mg} / \mathrm{Kg}$ & 0 & 0,8 & 1,20 & 1,30 & 1,30 \\
\hline (polvo naranja) & & & & & & \\
\hline Muestra 3 & $12,5 \mathrm{mg} / \mathrm{kg}$ & 0 & 0,85 & 0,85 & 0,90 & 0,90 \\
\hline (p. blanquecino) & & $\theta$ & & & & \\
\hline Piroxicam & $3,3 \mathrm{mg} / \mathrm{Kg}$ & 0 & 0,20 & 0,20 & 0,35 & 0,35 \\
\hline Dexametasona & $0,4 \mathrm{mg} / \mathrm{kg}$ & 0 & 0,20 & 0,20 & 0,20 & 0,20 \\
\hline & & & & & & \\
\hline
\end{tabular}

Valores de $\Delta V$ obtenidos del ensayo con las diferentes muestras y estándares FIG. $\mathbf{N}^{\circ} 4$ 


\section{EFECTO ANTINFLAMATORIO DE LAS MUESTRAS Y ESTANDARES}

ml.

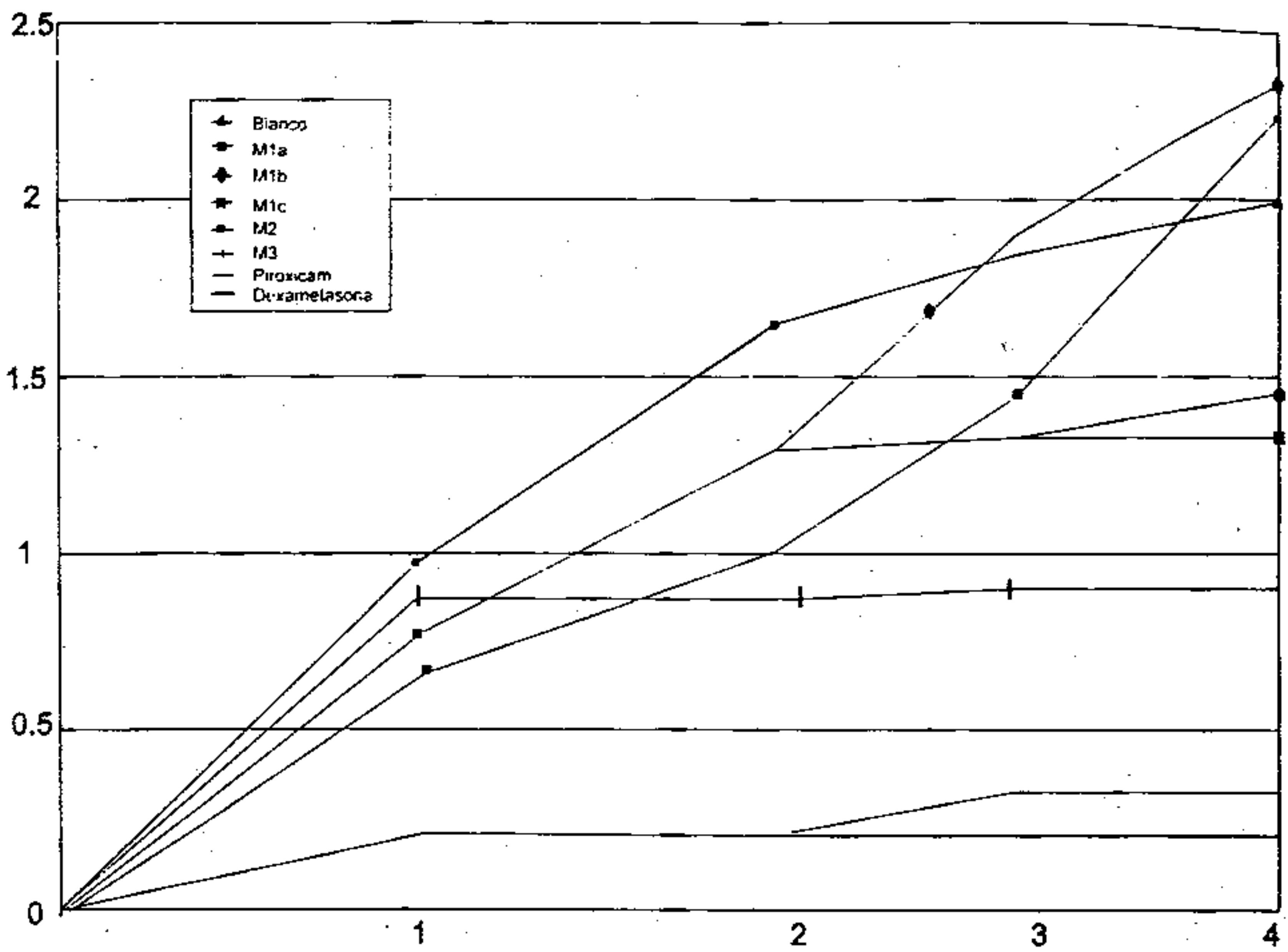

M1a= Curcumina $6,25 \mathrm{mg} / \mathrm{Kg} \quad$ M1b= curcumina $12,5 \mathrm{mg} / \mathrm{kg}$. M1c Curcumina $125 \mathrm{mg} / \mathrm{kg}$ M2= Extracto Metanólico de C. longa $\mathrm{ml} / \mathrm{Kg} \mathrm{M} 3=$ Curcuminoide no delerminado $12.5 \mathrm{~m} / \mathrm{kg}$ Piroxicam $=3.3 \mathrm{mg} / \mathrm{kg}$ Dexametasona $=0,4 \mathrm{~m} 1 / \mathrm{kg}$

FIG. $\mathrm{N}^{\circ} 5$

DISMINUCIÓN DE LA INFLAMCIÓN (Cuarta hora)

\begin{tabular}{|c|c|}
\hline GRUPO & $\%$ \\
\hline \hline Control & 0,0 \\
\hline M ta & 0,0 \\
\hline$M$ tb & 0,0 \\
\hline$M 1 \mathrm{c}$ & 27,5 \\
\hline Piroxicam & 82,5 \\
\hline Dexametasona & 90,0 \\
\hline
\end{tabular}

DISMINUCIÓN DE LA INFLAMACIÓN (Cuarta hora)

\begin{tabular}{|c|c|}
\hline GRUPO & $\%$ \\
\hline Control & 0,0 \\
\hline$M 2$ & 35,0 \\
\hline$M 3$ & 55,0 \\
\hline Piroxicam & 82,5 \\
\hline Dexametasona & 90,0 \\
\hline
\end{tabular}

FIG. $N^{\circ} 6$ 
DISMINUCIÓN DE LA INFLAMACIÓN (cuarta hora)

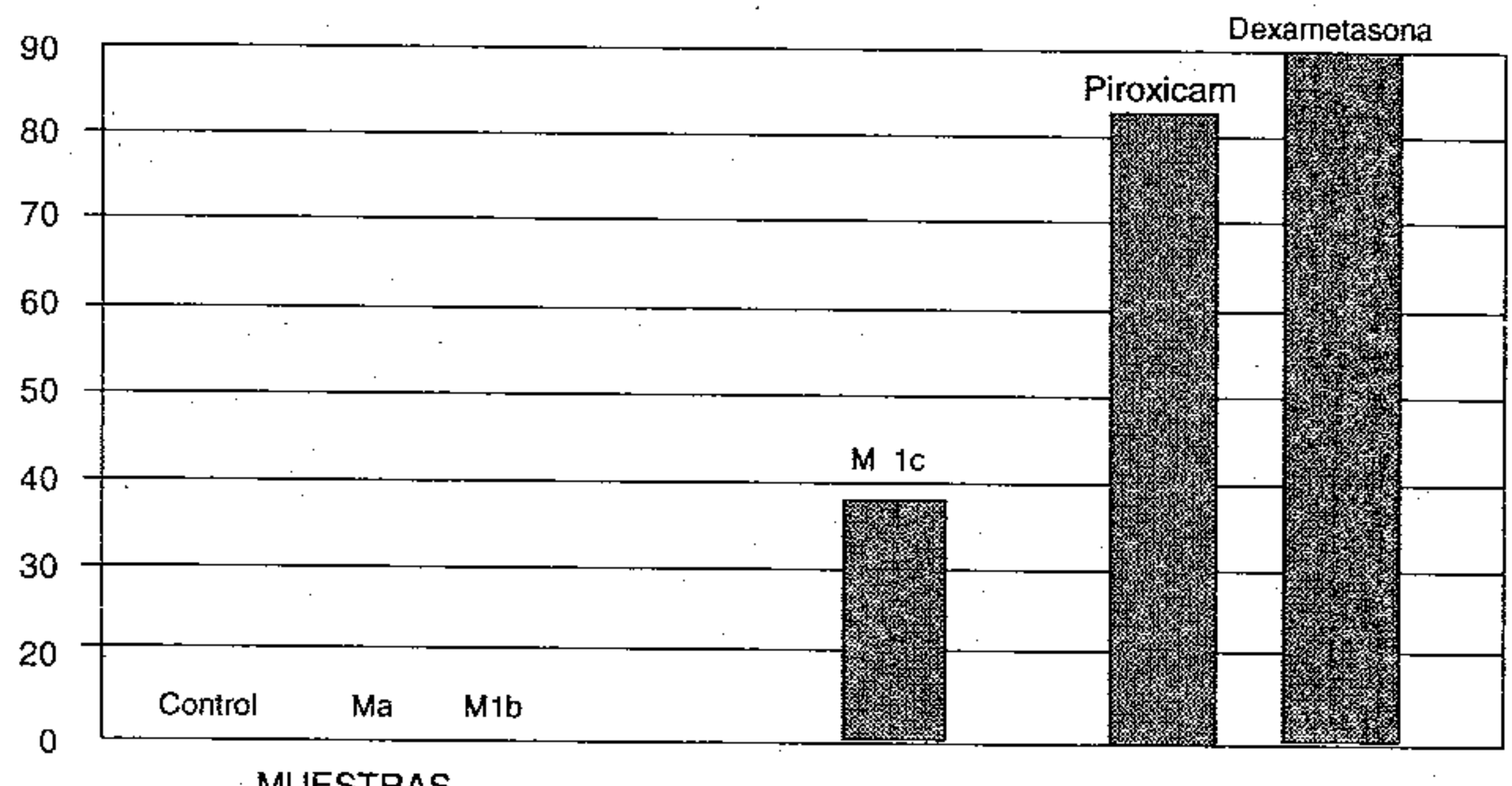

DISMINUCIÓN DE LA INFLAMACIÓN (cuarta hora)

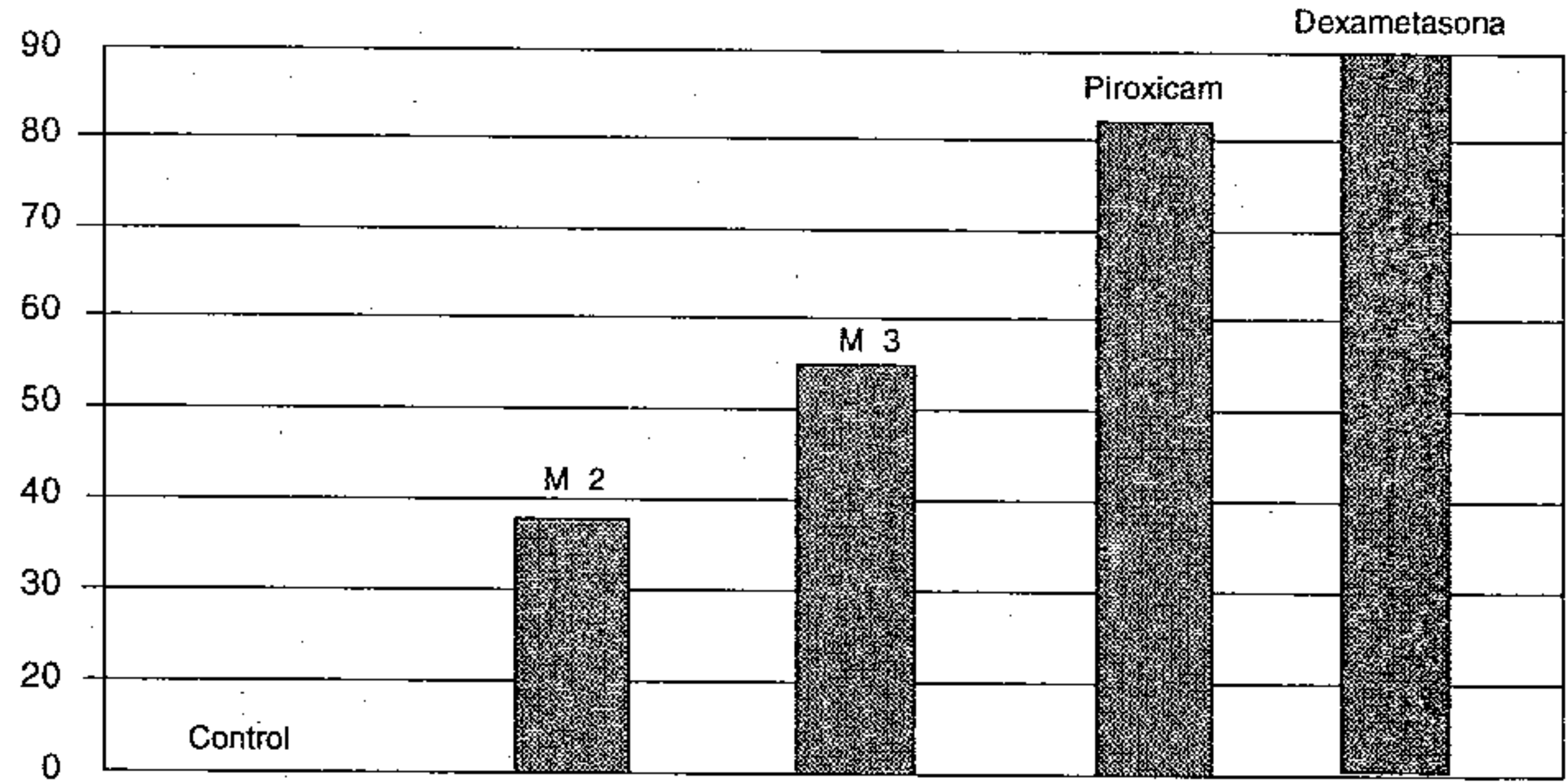

MUESTRAs

FIG. Na 7 


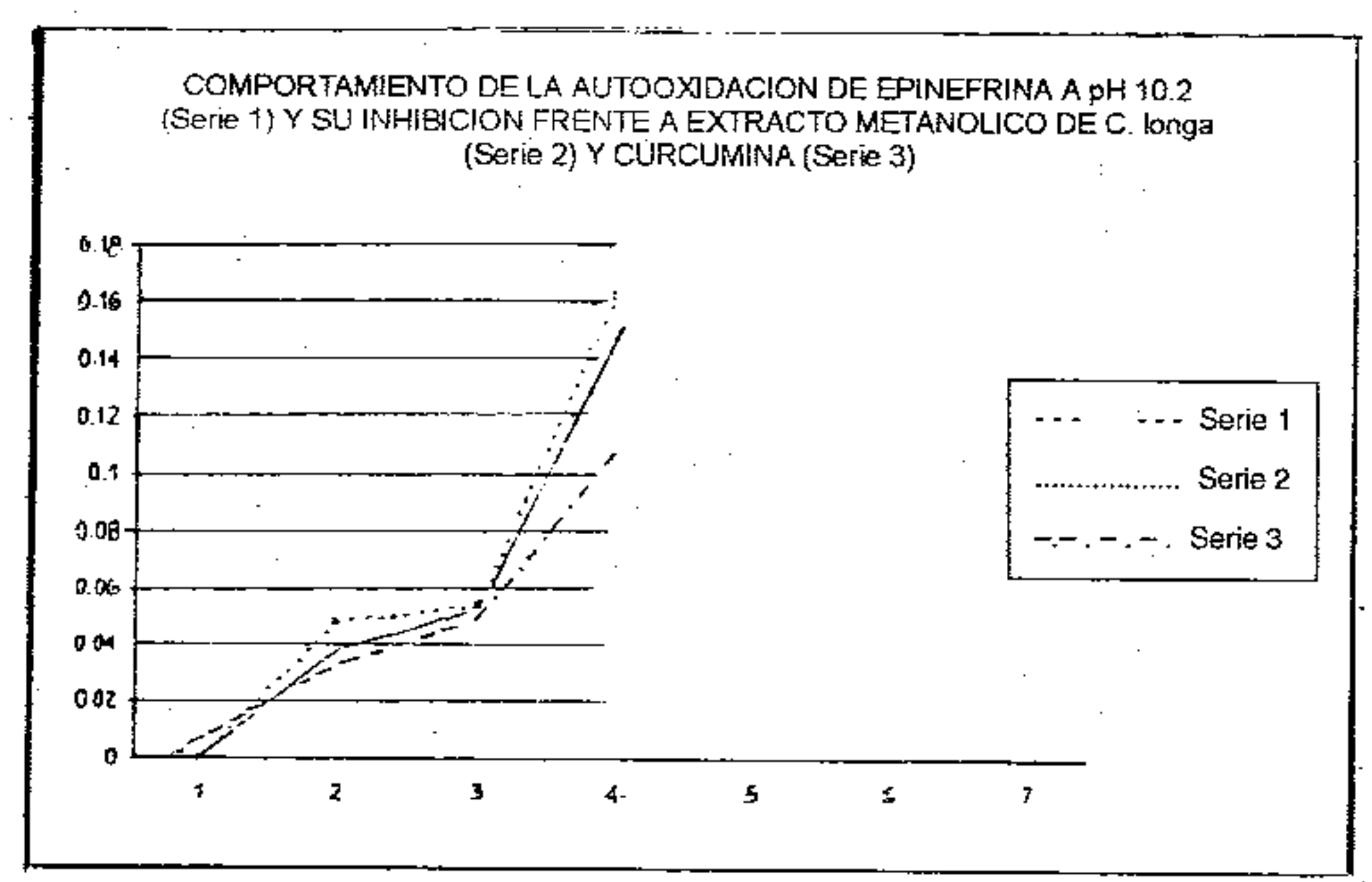

\begin{tabular}{|l|c|c|c|c|c|c|c|}
\hline \multicolumn{1}{|c|}{ TEMPO } & O mon & $1 \mathrm{~min}$ & $2 \mathrm{~min}$ & $3 \mathrm{~min}$ & $4 \mathrm{~min}$ & $5 \mathrm{~min}$ & $6 \mathrm{~min}$ \\
\hline Epinedrina + Buffer pH 10.2 & 0 & 0.048 & 0.054 & 0.161 & 0.102 & 0.057 & 0.040 \\
\hline Eṣinefrina + Extracto + Buffer $\mathrm{pH} 10.2$ & 0 & 0.038 & 0.052 & 0.150 & 0.99 & 0.055 & 0.052 \\
\hline Epinefrina + Curcumina + Buffer $\mathrm{pH} \mathrm{10.2}$ & 0 & & 0.050 & 0.107 & 0.065 & 0.029 & \\
\hline
\end{tabular}

Fig. N $^{\mathrm{a}} 8$

"Lo que gran parte de la ciencia moderna no advierte es que de poco sirve saber si no se piensa"

\author{
G. K. Chesterton
}

